\title{
150 AÑOS DE GEOGRAFÍA REGIONAL EN ARGENTINA: CAMBIOS Y CONTINUIDADES EN LAS PROPUESTAS DE REGIONALIZACIÓN DEL TERRITORIO NACIONAL (1839 A 1988)
}

\author{
150 years of regional geography in Argentina: changes and continuities in the \\ proposals of regionalization of the national territory (1839-1988)
}

\begin{abstract}
Alejandro Benedetti* y Esteban Salizzi**
\section{Resumen}

El presente artículo tiene como objetivo analizar las principales propuestas de regionalización del territorio argentino desarrolladas entre mediados del siglo XIX y finales del XX, buscando establecer una comparación que permita ofrecer claves interpretativas para el estudio del proceso de construcción conceptual del discurso regional nacional. Estas formulaciones se asentaron sobre una visión estática y centralista del país que, consolidada a lo largo de las primeras décadas del siglo XX, ha condicionado y distorsionado desde entonces - $\mathrm{y}$ aun hasta el presente- las interpretaciones de conjunto del territorio nacional a través de la hegemonización del discurso de las regiones geográficas argentinas. Finalmente, se presenta una serie de conclusiones acerca del modo en el que se ha pensado y repensado la geografía regional argentina, buscando esclarecer cómo esta ha servido de vehículo -a partir de su considerable permanenciapara la naturalización y posterior justificación de una imagen e interpretación (de las desigualdades internas) del país que se ha vuelto hegemónica a lo largo del siglo XX, y que solo recientemente comienza a ser seriamente cuestionada.
\end{abstract}

$$
<\text { Argentina }><\text { Pensamiento geográfico }><\text { Geografía regional }><\text { Región }>
$$

\begin{abstract}
This article aims to analyze the main proposals of regionalization of the argentine territory developed between the mid-nineteenth century and the late twentieth in order to establish a comparison that provides interpretive keys for the study of the process of conceptual construction of the regional national discourse. These formulations were settled on a static and centralist vision of the country, consolidated over the first decades of the twentieth century. This vision has conditioned and distorted since then -and even to the present- the interpretations of the national territory through the argentine geographic regions hegemonic speech. Finally, it presents a series of conclusions about the way that the regional geography of Argentina has been thought and rethought seeking to clarify how this has served as a vehicle-from its permanence- for the naturalization and subsequent justification of an image and interpretation (of the internal inequalities) of the country that has become hegemonic throughout the twentieth century and only recently has began to be seriously questioned.
\end{abstract}

$<$ Argentina $><$ Geographical thinking $><$ Regional geography $><$ Region $>$

Recibido: 03/08/2015 // Aceptado: 29/01/2016

\footnotetext{
* Instituto interdisciplinario de Tilcara Facultad de Filosofía y Letras. UBA-CONICET. alejandrobenedetti@outlook.com

** Instituto de Geografía "Dr. Romualdo Ardissone", Facultad de Filosofía y Letras, Universidad de Buenos Aires. esalizzi@filo.uba.ar
} 


\section{1) Introducción}

En el pensamiento geográfico argentino es común encontrar relatos dedicados a identificar, delimitar y caracterizar un conjunto de unidades espaciales (generalmente llamadas regiones) que, con origen en un pasado remoto, parecerían alcanzar nuestros días creando una falsa ilusión de continuidad y permanencia. El acto de regionalizar, de este modo, ha ocultado la historicidad de las regones, expresada tanto por el hecho de que toda propuesta de regionalización está siempre situada en un contexto geo-histórico y epistemológico específico, así como también por las características propias del espacio que -a pesar de su presentación/conceptualización como un objeto estático- se encuentra inevitablemente sometido a constantes procesos de transformación social. Uno de los elementos centrales que sustentan esta situación se encuentra en la influencia de la toponimia regional, que en el caso del territorio argentino conserva denominaciones de origen antiguo -incluso prehispánico-, tales como Pampa, Chaco, Puna, Mesopotamia, entre otras.

A su vez, esta persistencia alimenta interpretaciones de larga duración no solo en torno al reconocimiento de las características distintivas de dichas unidades, sino también acerca del modo en que estas áreas se integran y/o relacionan con el resto del país. Así, las regiones suelen ser presentadas como elementos dados, poseedoras de características sociales y naturales propias e inalterables, partes de un rompecabezas que conforma la regionalización en su conjunto y que, como tal, siempre completa el territorio de la Argentina, entidad que también se asume como una permanencia.

Estas formulaciones se asientan sobre una visión estática y centralista del país que, consolidada a lo largo de las primeras décadas del siglo XX, ha condicionado y distorsionado desde entonces $-\mathrm{y}$ aun hasta el presente- las interpretaciones de conjunto del territorio nacional a través de la hegemonización del discurso de las regiones geográficas argentinas. Su relato se ha retroalimentado por la gran influencia mostrada por las perspectivas fisiográfica y humana en el pensamiento geográfico argentino, que naturalizaron las regiones, presentándolas como escenarios estáticos antes que como construcciones sociales e históricas.

El presente artículo tiene como objetivo analizar las principales propuestas de regionalización del territorio argentino desarrolladas entre mediados del siglo XIX y finales del XX, buscando establecer una comparación que permita ofrecer claves interpretativas para el estudio del proceso de construcción conceptual del discurso regional nacional. La propuesta desarrollada consta de tres apartados. En el primero, se realiza una breve introducción al estudio de la tradición regional en geografía, a través de la identificación del modo en que esta temática ha sido abordada en los diferentes momentos epistemológicos de la disciplina. A continuación, se presentan y ordenan cronológicamente las principales y más significativas experiencias de regionalización del territorio nacional, buscando establecer tanto sus múltiples vinculaciones con el desarrollo de la geografía disciplinar en Argentina, como su importancia en la conformación del discurso regional nacional. Las obras analizadas en este apartado se dividen entre aquellas elaboradas durante el siglo XIX, desarrolladas principalmente 
por naturalistas de amplia formación; y las enunciadas durante el siglo XX por profesionales formados en el campo de la geografía. Finalmente, se presenta una serie de conclusiones acerca del modo en el que se ha pensado y repensado la geografía regional argentina, buscando esclarecer cómo esta ha servido de vehículo -a partir de su considerable permanencia- para la naturalización y posterior justificación de una imagen e interpretación (de las desigualdades internas) del país que se ha vuelto hegemónica a lo largo del siglo XX, y que solo recientemente comienza a ser seriamente cuestionada.

\section{2) La tradición regional}

Las ideas y prácticas relativas a las regiones integran el imaginario geográfico desde incluso antes de su institucionalización académica, formando parte activa de los saberes que constituyen su tradición disciplinar. La delimitación de porciones discretas de la superficie terrestre, más allá de la denominación que se les otorgue a dichas unidades (regiones, provincia, áreas, zonas, distritos, territorios, comarcas, etc.), es una actividad que sin dudas ha precedido la ritualización de la regionalización (Livingstone, 1992), una práctica que se desarrolló con fuerza en el seno de la geografía disciplinar durante la primera mitad del siglo XX.

Conviene, entonces, partir de la premisa de que una región es, en principio, el resultado de la distinción de una parte dentro de un todo, a través de la definición de uno o más criterios que permitan reconocer y sistematizar ciertos elementos de semejanzahomogeneidad-cohesión hacia su interior y de diferencia-heterogeneidad-desunión hacia su exterior.

Ahora bien, en un orden directamente proporcional con la antigüedad de esta preocupación, se encuentra a su vez la importancia para la geografía académica que han tenido tanto en términos cualitativos como cuantitativos los debates motivados por el concepto de región y el recurso de la regionalización. Al respecto, cabe señalar que ninguna de sus principales tendencias epistemológicas se ha privado de teorizar acerca de su significado, el cual ha estado recurrentemente vinculado con el problema mismo de la definición de un objeto y métodos distintivos para la geografía (García Álvarez 2006).

A lo largo del proceso de formación de su campo disciplinar pueden reconocerse, sintéticamente, al menos seis perspectivas regionales vinculadas tanto a la influencia desplegada por la preeminencia de diferentes perspectivas epistemológicas, distintos lógicas de delimitación del espacio, como al diálogo e interacción con otros campos científicos (Benedetti, 2009). En este punto se considera pertinente resaltar que, en orden con lo señalado por Heffernan (2009) acerca de la inexistencia de una única historia de la geografía como disciplina, la enumeración y descripción de las principales perspectivas regionales que se presentarán a continuación -y de sus respectivos marcos epistemológicos- no debe ser leída como una secuencia lineal de cambios radicales o revolucionarios, que estarían implicando el reemplazo de unas por otras. Por el contrario, representa un proceso de acumulación, en el que una diversidad de saberes y tradiciones se incorporan, superponen y coexisten junto a desarrollos posteriores para 
crear un panorama disciplinar cada vez más rico y complejo. Desde mediados del siglo XIX hasta el presente se pueden identificar seis momentos epistemológicos en los cuales se abrevó en una propuesta regional renovadora con respecto a lo precedente:

I. Enfoque fisiográfico. El primer antecedente académico de la práctica de la regionalización se ubica hacia mediados del siglo XIX con la profesionalización de la geología. En ese marco, la identificación de regiones naturales o físicas -desarrollado inicialmente por la tradición fisiográfica alemana-suponía la división del medio natural a partir de la consideración de unidades donde el conjunto de los elementos naturales (la hidrografía, la climatología, la geomorfología y la biogeografía) alcanzarían un cierto equilibrio. La aplicación de esta noción al estudio de un territorio estatal resultaba en su subdivisión, y la obtención de un mosaico con límites precisos que cubría su totalidad. Las regiones naturales no se vinculaban con los límites jurisdiccionales internos -sí con los externos- ni reconocían conexiones causales con los aspectos de la geografía humana.

II. Enfoque humanista. Tomando como punto de partida la noción de región natural, a principios del siglo XX la escuela regional francesa (referente de la Geografía Humana clásica) buscó resaltar las distintas formas en que los grupos humanos aprovechaban la naturaleza, a través de la técnica y de diversas formas organizativas. Así, desde su perspectiva, de la interacción entre el hombre y la naturaleza -de larga duración- surgía un paisaje y un modo de vida plausible de ser individualizado, delimitado y descripto. En la noción de región geográfica, hacia la década de 1940, se condensó una idea de síntesis entre regiones naturales y acciones humanas, conformando unidades que reunían rasgos que le otorgaban identidad propia y las diferenciaban del resto, operando así como ciencia idiográfica. De igual modo que sucedía con las regiones fisiográficas, la práctica de regionalización suponía la partición total del territorio nacional, formando un mosaico continuo, sin espacios residuales. En ese momento, se propició una transformación epistemológica trascendental al ubicar a la regionalización como el principal asunto de la geografía disciplinar.

III. Enfoque analítico. Otra perspectiva, impulsada hacia mediados del siglo XX por los estudios cuantitativos en geografía, puso el énfasis en la polarización que ejercen ciertas localizaciones en la organización del espacio. La región polarizada estaba constituida por un lugar central y por su área de influencia, el hinterland. Esta lógica de regionalización se diferenciaba de las anteriores en que no se basaba en factores naturales o culturales objetivos, sino en la dinámica funcional del espacio, el cual era entendido como una superficie abstracta, isótropa y ahistórica. De este modo, a diferencia de lo que sucedía con las perspectivas previamente señaladas, las regiones dejan de ser consideradas exclusivamente como entidades ontológicas para comenzar a ser empleadas también como artilugios metodológicos al servicio del análisis espacial.

IV. Enfoque humanístico. Desde la perspectiva fenomenológica, impulsada por las geografías del sujeto (o humanísticas) en respuesta a la pretendida exclusividad del conocimiento científico de la geografía cuantitativa, la región pasa a ser concebida como un espacio de vida, íntimamente relacionado con la experiencia personal. En este 
caso, la diferenciación geográfica estaba asociada a la subjetividad de los individuos, a su percepción, a la construcción del espacio como algo socialmente significativo, como un ámbito de identidad. Así, la región se confunde con la noción de lugar.

V. Enfoque radical. Otra respuesta ensayada al interior de la disciplina a partir de la crítica a las geografías analíticas provino de las denominadas geografías radicales y marxistas. La región desde la perspectiva de la economía política buscaba dar cuenta de las desigualdades espaciales surgidas como consecuencia del avance del modo de producción capitalista. Aquí, nuevamente, se advierte un cambio substancial en la concepción del espacio, que deja de ser considerado como el resultado de la influencia del medio natural o como un concepto relativo, para ser concebido como la derivación de una construcción social, de un conflictivo proceso histórico.

VI. Enfoque político-cultural. Finalmente, desde mediados de la década de 1980, -y en concordancia con la revitalización de las geografías políticas y regionales, así como con las implicancias del denominado "giro cultural en geografía"- los estudios regionales comenzaron a tener una fuerte impronta política, histórica y cultural. La región político-cultural recupera la idea de la construcción subjetiva del espacio, a partir de determinados dispositivos de poder, ya no por un sujeto individual, sino colectivo. Se observa un énfasis en la historicidad de las regiones, lo que lleva a considerarlas ya no como realidades fijas, sino como procesos abiertos, dinámicos, contingentes, en permanente transformación a partir de las prácticas materiales y simbólicas de la sociedad. Bajo esta perspectiva, si bien no se desconoce la dimensión material de la región, el mayor énfasis se encuentra en la dimensión simbólica, en el estudio de los imaginarios y las narrativas regionales. Finalmente, y en orden con los elementos antes introducidos, las categorías regionales forman parte del entramado de las relaciones sociales, no son productos externos a la sociedad, ni se forman en instancias previas o posteriores a los acontecimientos sociales. Así, no sólo la región como espacio social tiene su historia, sino también como idea, como categoría, como nombre (topónimo). Allí radica, entonces, el desafío de proponernos problematizar e indagar acerca de estas unidades. Vale decir: nos posicionaremos en este enfoque para encarar la revisión de la tradición regional argentina.

\section{3) La tradición regional argentina}

La primera tentativa de división del territorio argentino (por entonces Confederación Argentina), como paso previo para describir sus desigualdades espaciales internas, fue publicada en el año 1852 en Buenos Aires, y fue escrita por el cónsul británico Woodbine Parish. Desde entonces y hasta el presente se han ensayado numerosas propuestas de regionalización que, siguiendo un eje temporal, pueden agruparse del siguiente modo:

a) Segunda mitad del siglo XIX. Primeras regionalizaciones ensayadas por naturalistas extranjeros que realizaron estadías prolongadas en el país. Subyace a estas propuestas un enfoque fisiográfico. 
b) Décadas de 1900 a 1930. Regionalizaciones publicadas por geógrafos europeos que realizaron estadías no muy prolongadas en la Argentina. Pervive el enfoque fisiográfico, pero se introduce el humano.

c) Décadas de 1940 a 1960. Regionalizaciones producidas por los primeros geógrafos profesionales argentinos. Conviven ambos enfoques, aunque gana preeminencia el humano.

d) Década de 1960 a 1980. Regionalizaciones realizadas por una segunda generación de geógrafos argentinos, que no se aparta sustancialmente de los anteriores. Introducen algunos elementos del enfoque cuantitativo y del enfoque de la economía política.

Los trabajos académicos sistemáticos que abordaron, directa o indirectamente, el estudio de la tradición regional argentina tendieron a concentrarse en los tres primeros períodos (González Bollo 1999, Navarro Floria 1999 y 2008, Barsky 2000, Velázquez 2001 y 2008, Navarro Floria y Mc Caskill 2001, Quintero 2002a y 2002b, Souto 2003, Souto y Ajón 2004, Navarro Floria y Williams 2010, Benedetti 2010 y 2014, Carballo 2012, Salizzi 2012). Estos trabajos, a su vez, presentan un importante caudal de información referente al perfil profesional de cada uno de los autores que en estos períodos se destacaron por sus propuestas de regionalización del país, los cuales son recuperados a continuación, pero omitiendo dichos comentarios. Si bien tienen un gran valor contextual, restan espacio al análisis y comparación de sus trabajos.

a) Regionalizaciones previas a la institucionalización de la geografía en Argentina

A lo largo del siglo XIX fueron ganando importancia las denominadas geografias argentinas (Quintero, 2002b), género narrativo que respondía fundamentalmente a la necesidad de las potencias coloniales europeas de poder contar con visiones de conjunto de un país en formación. En ellas comenzaron a ensayarse las primeras regionalizaciones del territorio nacional, aunque todavía sin un peso explicativo trascendental, el cual continuaba residiendo en la diferenciación provincial. Estos trabajos, que presentan una fuerte impronta del naturalismo decimonónico europeo, a través del perfeccionamiento de la regionalización desde esta perspectiva, dan origen a la noción de región natural.

Las geografias argentinas de la segunda mitad del siglo XIX fueron producidas por Woodbine Parish (1839 [traducido al español en 1852]), Alfred du Graty (1858), Victor Martin de Moussy (1864), Hermann Burmeister (1876), Richard Napp (1876) y Francisco Latzina (1888) (ver Cuadro 1). Estos autores eran extranjeros que realizaron estadías más o menos prolongadas en el país. Sus trabajos resultan emblemáticos ya que muchos de ellos iniciaron la construcción de muchas de las categorías regionales que aún perduran, como Mesopotamia, Pampa y Puna. Cabe destacar que tanto A. Du Graty como F. Latzina no ofrecieron regionalizaciones para la escala nacional, razón por la cual sus trabajos no serán considerados en el análisis que se propone a continuación. Asimismo, R. Napp no ofrece una propuesta que se aparte notablemente con respecto a H. Burmeister. De acuerdo a lo señalado por Navarro Floria y Mc Caskill (2001), 
la diferencia más profunda entre ambas descripciones radicaba en la valoración (en términos productivos) que se hacía del territorio pampeano y patagónico, optimista en el primero y pesimista en el segundo.

Tomando como criterios básicos la posición, la historia y las divisiones administrativas, W. Parish (1839) divide a la Confederación Argentina en tres unidades: I) las provincias ribereñas, II) las provincias de arriba y IV) las provincias de Cuyo. A pesar de que W. Parish no realiza una regionalización basada sobre los postulados de una disciplina, elabora un agrupamiento de las provincias confederadas con Buenos Aires en el que puede reconocerse la gran importancia adjudicada a los tradicionales itinerarios trazados a partir de Buenos Aires hacia Santiago de Chile (Cuyo), Asunción (ribereñas) y el Alto Perú (arribeñas) (Navarro Floria, 1999). Para la delimitación de las regiones utiliza los límites provinciales, sin ofrecer mayores precisiones al respecto. $\mathrm{Si}$ bien su trabajo no ofrece un mapa en el que se presentan las regiones por él construidas, incluye uno de la Confederación Argentina producido por John Arrowsmith en base a anotaciones, relevamientos y a cartografía recopilada por el propio Parish. En la Figura 1 se presenta una reconstrucción de dicha regionalización.

La obra de V. Martin de Moussy (1864) tuvo gran influencia en el pensamiento geográfico de la segunda mitad del siglo XIX, tanto por su aprovechamiento para la elaboración de descripciones del país como para tareas tales como la delimitación de su territorio (Hevilla, 2007). Su obra ofrece un cambio con respecto a la de W. Parish, al proponer un criterio de regionalización basado en el medio natural y no en la división jurisdiccional (Quintero, 2002b). Divide, así, al territorio nacional en cuatro regiones: I) Mesopotamia argentina, II) Región de las Pampas o Pampasia, III) Región de los Andes, y IV) Patagonia. De esta forma, tiene la particularidad de ser el primer trabajo en diferenciar la región de las Pampas de la Mesopotamia (Navarro Floria, 1999), espacio hasta entonces considerado genéricamente como litoral. También, menciona por primera vez a la Patagonia como una entidad espacial perteneciente a la Argentina, si bien no avanza en su descripción debido al escaso conocimiento que en su época se tenía de ella, dado que todavía no estaba efectivamente incorporada al territorio nacional. Si bien sus "regiones geográficas" responden a un criterio eminentemente fisiográfico, no concede importancia a establecer límites puntuales sino que lo hace en términos generales (referenciando mayormente límites naturales), recurriendo en todos los casos a la demarcación a través de la latitud y la longitud. Organiza su trabajo iniciando su recorrido descriptivo por los límites de la Confederación; luego se detiene en los aspectos generales del territorio nacional; sigue con una sección donde reconoce las regiones geográficas del país; y, finalmente, realiza una descripción pormenorizada de cada provincia. En la Figura 2 se presenta una reproducción de su mapa de regiones.

H. Burmeister (1876) establece cuatro agrupaciones de provincias, que denomina grandes divisiones naturales del territorio argentino: I) Las tres provincias septentrionales: Jujuy, Salta y Tucumán; II) Las cuatro provincias occidentales de la región de la Cordillera: Catamarca, La Rioja, San Juan y Mendoza; III) Las tres provincias centrales: San Luis, Santiago del Estero y Córdoba; y IV) Las cuatro 
provincias orientales: Corrientes y Entre Ríos -la Mesopotamia argentina-y las provincias pamperas de Santa Fe y Buenos Aires. A pesar de fundamentar su regionalización en criterios naturales, mantiene para la construcción de las unidades regionales la impronta jurisdiccional. En este orden, a la hora de hacer una descripción detallada del medio natural esta organización no cumple una función analítica de consideración. A su vez, el autor no publica en su trabajo un mapa en el que se presenten las unidades regionales antes señaladas. En la Figura 3 se reconstruye el agrupamiento de provincias por él propuesto.

Cuadro 1. Las primeras regionalizaciones del territorio nacional (segunda mitad del siglo XIX)

W. Parish (1839)

\begin{tabular}{ccc}
\hline 1- Provincias ribereñas & 1- Mesopotamia Argentina & $\begin{array}{c}\text { 1- Provincias orientales } \\
\text { (Mesopotamia argentina y provincias } \\
\text { pamperas) }\end{array}$ \\
\hline 2- Provincias de arriba & 2- Región de las Pampas o Pampasia & 2- Provincias centrales \\
\hline 3- Provincias de Cuyo & 3- Región de los Andes & 3- Provincias septentrionales \\
\hline & 4- Patagonia & $\begin{array}{c}\text { 4- Provincias occidentales de la } \\
\text { región de la Cordillera }\end{array}$ \\
\hline
\end{tabular}

Figura 2

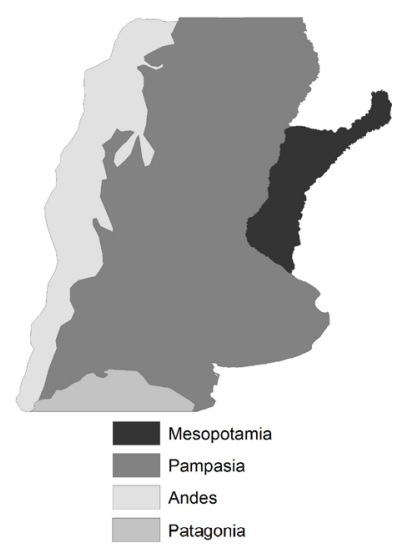

Figura 3

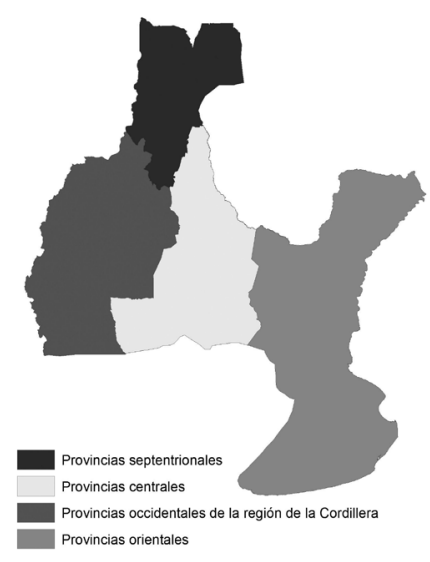

Fuente: Elaboración propia en base a Parish (1839), Martin de Moussy (1864) y Burmeister (1876). Cartografía digital: Pablo Maestrojuan.

Con distinta suerte, estas obras fueron las primeras narraciones de conjunto de la geografía argentina, producidas en distintos momentos del proceso de organización nacional (Quintero, 2002a). Proporcionan un cambio importante con respecto al que había sido hasta el momento el principal género literario en geografía: los relatos de viaje producidos mayormente por ingleses. A diferencia de estas obras, en las geografias nacionales la narración no está organizada por un sendero o itinerario, sino por un proceso previo de clasificación de áreas, vale decir, de alguna clase de regionalización, siguiendo dos criterios: jurisdiccional y fisiográfico. El primero siempre está presente y se manifiesta como la mejor alternativa para organizar el índice al momento de ofrecer descripciones detalladas. El segundo fue propuesto por V. Martin de Moussy, H. 
Burmeister y R. Napp y, en ninguno de los tres casos, se usa como criterio explicativo a todos los fines, sino para dar cuenta de la organización del medio natural a la escala del país.

Otras obras producidas en ese período, como la mencionada de Latzina (1888), mantienen como criterio central para la organización de sus trabajos -y por ende tanto para la descripción del territorio argentino como para el abordaje de sus asimetrías internas- la secuencia de provincias y territorios nacionales, sin recurrir de este modo a agrupamientos específicos de ningún tipo.

En las obras de este periodo, en las que se establecen regionalizaciones, estas constituyen una sección relevante dentro de estos trabajos. En ellas se utilizan categorías geofísicas elementales que definen la clave de la diferencia principal entre regiones, tales como llanuras, mesetas y cordilleras. De todas formas, como ya fue señalado, se aprecia todavía el predominio de la división provincial (político-administrativa) como principal criterio para la organización de la narración. De este modo, y frente al aparente eclecticismo de criterios que caracteriza a los trabajos presentados, puede afirmarse que estas propuestas se formulan desde un enfoque regional pre-disciplinar, donde las divisiones geográficas reconocidas responden, todavía, a una elección práctica, sin una clara finalidad epistemológica (Paasi, 2002).

b) Regionalizaciones de la Argentina elaboradas por geógrafos europeos

Los diferentes enfoques regionales europeos de fines del siglo XIX e inicios del XX, llegaron a la Argentina, en momentos sucesivos, a través de la incorporación de geógrafos profesionales allá formados a diversas instituciones nacionales. Los más destacados fueron Enrique Delachaux (1908), Pierre Denis (1920) y Franz Kühn (1930), que transformaron la forma en la que se pensaba al espacio argentino de acuerdo a los nuevos cánones de la disciplina geográfica (ver Cuadro 2).

Delachaux (1908:102) afirmaba que "al empezar la descripción de un país y para simplificar la tarea, es de regla subdividirlo previamente en regiones naturales [...] La subdivisión en regiones naturales es, para la geografía física y aun política lo que el índice para un libro". De este modo, propuso una división de la Argentina en cuatro regiones fisicas o naturales (Figura 4), manteniendo la tendencia a identificar unas pocas unidades.

El geógrafo francés P. Denis, en cambio, introdujo en la Argentina la tradición humana de Paul Vidal de la Blache. En su propuesta de regionalización, las claves explicativas se encontraban en la acción del hombre como transformador del medio natural. En el primer capítulo de su libro (cf. Denis, 1920), se dedica a las regiones naturales, e incluye una sección donde identifica los que considera como los componentes básicos del paisaje argentino y que contribuyen a la diversidad del medio natural: la montaña, la llanura y el río. Según el autor, "la colonización y los esfuerzos y tanteos de la industria humana para adaptar las prácticas agrícolas o pecuarias a las condiciones naturales, son los que permiten delimitar las regiones naturales. En 
Benedetti y Salizzi. 150 años de geografía regional en Argentina: cambios y continuidades en las propuestas de...

la diferenciación entre regiones naturales, el papel de la historia es esencial" (Denis, 1920:57). Así, la principal diferencia con el enfoque de sus predecesores radica en la importancia adjudicada a la acción humana y al devenir histórico, sin por ello abandonar la detallada descripción del medio natural. Identifica para la Argentina cinco regiones, una más que sus antecesores (Figura 5), resaltando -en algunos casos- en su misma denominación los rasgos que le otorgaban personalidad, fruto de los modos de vida allí desarrollados. A su vez, y a diferencia de sus predecesores, comienza a otorgarle importancia conceptual a los límites entre regiones, al afirmar que las actividades humanas dan un sentido geográfico a los límites (climáticos/naturales) hasta entonces no advertidos. En palabras del autor estos límites “...permanecen inciertos algún tiempo, y poco a poco la experiencia y la tradición terminan por consagrarlos. Siempre conservan una elasticidad, adelantándose o retrocediendo según sea más o menos favorable el mercado de los productos cosechados" (Denis, 1920:61).

Más influyente en el desarrollo de la geografía argentina fue la obra Kühn(1930), quien introdujo la perspectiva fisiográfica alemana. Consideraba que las estructuras geológicas tenían una función central en el modelado de la superficie terrestre. El itinerario analítico, pues, se inicia con la descripción de las estructuras geológicas, para luego seguir con el clima, la flora y la fauna. Proponía que "cada una de esas regiones naturales tiene su carácter definido en atención a sus rasgos topográficos, a su régimen hidrográfico, cantidad de lluvias y tipo de la vegetación espontánea" (Kühn, 1930:52). Puede reconocerse a lo largo del trabajo de este autor la importancia que adquieren los factores naturales, y la presencia de un suavizado discurso determinista, que los enlaza con la realidad social descripta. Su propuesta divide al país, ya no en cuatro o cinco unidades, sino en once regiones (Figura 6).

Si la regionalización en buena parte de la producción geográfica de la segunda mitad del siglo XIX no tenía una finalidad epistemológica, en las primeras décadas del siglo XX esto cambia radicalmente. A su vez, mientras que en las obras de geografía argentina del siglo XIX se presentaba un mapa regional conformado por la agregación de provincias y gobernaciones, ya en el siglo XX la lectura geográfica se regirá, definitivamente, por un mapa de regiones naturales, diferente del provincial. Con estos autores la regionalización se institucionaliza como forma fundamental para abordar el estudio geográfico del país. Se instaura de este modo una noción de diferenciación espacial que se resuelve siempre en un rompecabezas cuyas piezas encastran perfectamente y nunca rebasan los límites nacionales (Quintero, 2000a). Otra consideración que se instala, y permanece, se relaciona con los límites, los cuales siempre son definidos, estables y continuos (igual que los de las provincias). Asimismo, pocas veces se da cuenta debidamente del procedimiento a través del cual los límites son establecidos, considerados como elementos dados por la propia naturaleza analizada y no como el producto de la aplicación de una cierta metodología. 
Cuadro 2. Las primeras regionalizaciones geográficas del país (décadas 1900 a 1930)

E. Delachaux (1908)

P. Denis (1920)

F. Kühn (1930)

1- Litoral \begin{tabular}{c} 
1- La llanura pampeana \\
\cline { 2 - 4 } 2- Central o mediterránea
\end{tabular}

Fuente: Elaboración propia en base a Delachaux (1908), Denis (1920) y Kühn (1930). Cartografía digital: Pablo Maestrojuan.

c) Regionalizaciones de la Argentina realizadas por los primeros geógrafos argentinos

Las obras de los geógrafos europeos, mencionadas precedentemente, influyeron en la formación de sucesivas camadas de geógrafos argentinos -como Romualdo Ardissone, Federico Daus, Horacio Difrieri y Elena Chiozza-, quienes contribuyeron a institucionalizar y volver hegemónicas las perspectivas regionales introducidas al país, en particular, por F. Kühn y por P. Denis. La relevancia adquirida por el pensamiento regional en el ámbito académico derivó en este periodo en su transferencia al sistema educativo, introduciendo ampliamente el concepto de región en los programas de geografía escolar. El papel decisivo que tuvo la Sociedad Argentina de Estudios 
Benedetti y Salizzi. 150 años de geografía regional en Argentina: cambios y continuidades en las propuestas de...

Geográficos (GÆA) en la reelaboración de los planes de estudios y la producción de los libros de enseñanza de geografía fue analizado por Zusman (1997), Souto (1996) y Quintero (1999). El programa escolar de enseñanza de la geografía de 1926 introdujo el enfoque fisiográfico (Escolar, Quintero y Reboratti, 1994). Hasta entonces, las divisiones políticas provinciales, ordenadas alfabéticamente, estructuraban el entendimiento de las diferencias internas del país. Ese año se produjo, en palabras de Daus, una "importante reforma en la enseñanza de la Geografía porque se pasó a una geografía de base científica, en sustitución de la puramente descriptiva" (Daus, 1969:37).

Las regionalizaciones más representativas de este período fueron elaboradas por Federico Daus (1945, 1957), Joaquín Frenguelli (1946), Horacio Difrieri (1958) (ver Cuadro 3).

Fue F. Daus quien transformó a las regiones en la quintaesencia de la geografía argentina. Este autor produjo un importante clivaje al introducir la perspectiva humana y conducir, con ello, al reemplazo en los programas educativos de geografía de la categoría región natural por la de región geográfica -noción adaptada de la propuesta por el geógrafo norteamericano Richard Hartshorne-. En palabras del autor, la región geográfica "se refiere a una suma de caracteres físico-geográficos y antropo-geográficos que individualizan un área de la superficie terrestre" (Daus, 1957:19). Fue bajo esta perspectiva que la geografía regional, articulada con el pensamiento geopolítico, se volvió dominante en la producción disciplinar argentina. Con fuentes de inspiración eclécticas, F. Daus comenzó a elaborar su propuesta regional en la década de 1930 (Daus, 1935), pero el reemplazo de la noción de región natural por la de región geográfica en los programas oficiales de geografía finalmente ocurrió en la década de 1950. Para entonces ya había publicado dos obras de trascendental importancia. Desde entonces, varias generaciones de argentinos se socializaron en la escuela aprendiendo el ritual de la regionalización, que parecía ser la única opción posible para conocer e interpretar las diferencias internas del país -donde cada región se distinguía de las otras por poseer una personalidad singular y por tener una posición única dentro de la totalidad nacional-. De este modo, el pasaje de la región natural a la región geográfica no representaba solamente un cambio de rótulo, sino también de concepción, ya que más que una función heurística u epistemológica buscaba tener ahora un sentido legitimador de la disciplina.

El primero de sus trabajos a los que se hará referencia (Daus, 1945), es un libro de enseñanza de la geografía para el ciclo medio. El libro estaba dividido en dos partes: física y humana. El estudio del país era realizado por capas, analizando primero los rasgos geológicos, luego los climáticos, los hidrográficos y los biogeográficos, para finalmente presentar, en la primera parte, su propuesta de regionalización, que constaba de ocho regiones geográficas. A su vez, en 1957 publicó otro trabajo, con un perfil más académico, en el que termina de definir su propuesta de regionalización. El mapa de regiones geográficas que presenta en dicho trabajo (Figura 7) tiene la particularidad, a diferencia de lo que sucedía con los otros autores hasta el momento analizados, de no tomar como base la división provincial de la Argentina. De este modo, la clave de diferenciación fundamental al interior del país se establece exclusivamente en las 
regiones geográficas reconocidas por el autor. Otro elemento que diferencia el trabajo de F. Daus de sus antecesores, se encuentra en la relevancia que le atribuye a la definición de los límites entre regiones, los cuales considera de dos tipos: "por transfiguración" y "por contraste". Así, afirma que en "...el cuadro regional es fuente de confusión la dificultad existente para establecer los límites de región a región, que figuradas convencionalmente por líneas de trazado neto, son en realidad, las más de las veces, franjas de transfiguración en las cuales están, precisamente, los límites antedichos." (Daus, 1957:85). Curiosamente, esta clasificación a la que recurre para la delimitación de las regiones solo es aplicada al interior del país, ya que aquellas que se ubican sobre los límites internacionales no cumplen con este criterio.

J. Frenguelli publicó en la obra colectiva "Geografía de la República Argentina” (1946), editada por la Sociedad Argentina de Estudios Geográficos, un capítulo destinado al estudio de las grandes unidades físicas del territorio argentino. Al igual que otros autores, revisó las regionalizaciones precedentes de su propuesta (incluyendo la que se presentó con el censo nacional de población de 1895 [Bavio, 1898] y excluyendo curiosamente la desarrollada por P. Denis). Según su punto de vista, las sucesivas regionalizaciones naturales permiten un mejor conocimiento del territorio argentino y conducen a una mayor precisión en su definición. De todas formas, considera que, hasta entonces, todas esas obras ofrecían un "conocimiento incompleto de la inmensa extensión del territorio nacional" (Frenguelli, 1946:22). En este orden, su división natural del territorio argentino tiene el objetivo de presentar una propuesta de regionalización que sea superadora. Basa su división en dos órdenes de criterios: (a) morfológicos y genéticos, y (b) accesorios. A través de estos elementos reconoce tres unidades principales del paisaje natural (planicies, montañas e islas), que dan origen a once regiones -igual número de Kühn-, algunas de las cuales son susceptibles de ser divididas en subregiones (Figura 8). Una cuestión a destacar es la incorporación de un área que no estaba contemplada en los trabajos previos, las Islas Malvinas, que son mencionadas dentro del conjunto paisajístico de las islas costeras. Si bien el autor no avanza sobre consideraciones geopolíticas, ya su inclusión da cuenta de la agenda de temas que interesan a la Sociedad Argentina de Estudios Geográficos. En lo que respecta a los límites entre regiones, la delimitación busca presentar un carácter preciso, expresado cartográficamente con líneas continuas, fijas; de todos modos, no aborda analíticamente nada relativo a su determinación.

Otra regionalización del país, basada en criterios naturales, que resulta relevante destacar a los fines del presente trabajo, fue la presentada por H. Difrieri en el marco de la obra colectiva "La Argentina. Suma de geografía" (1958). De igual modo que J. Frenguelli, inicia su trabajo revisando las propuestas regionales que constituyen, desde su punto de vista, los antecedentes de su trabajo (Parish, Martin de Moussy, Burmeister, Napp, Delachaux, Kühn, entre otros). La propuesta desarrollada por H. Difrieri consiste en la división del territorio nacional en trece regiones naturales o divisiones mayores (Figura 9). Señala, en este orden, que cada “...región es única y no puede entrar en un esquema clasificatorio del tipo linneano, por extensión del concepto, en virtud de que la 
Benedetti y Salizzi. 150 años de geografía regional en Argentina: cambios y continuidades en las propuestas de...

ciencia que la maneja es una ciencia idiográfica y no una ciencia nomotética." (Difrieri, 1958:361). A pesar de no realizar una explicitación precisa del enfoque utilizado para realizar su regionalización, en sus postulados se advierte una preeminencia fisiográfica que toma como criterio rector a las grandes estructuras geomorfológicas. El autor afirma que son dos las entidades que ordenan el territorio argentino: los altos relieves y las extensas planicies (Difrieri, 1958:362). Al igual que J. Frenguelli incluye las Malvinas dentro de sus unidades, incorporando, a su vez -y como novedad-, a la Antártida Argentina. A diferencia de otros autores de este periodo, la cuestión de los límites no es abordada.

Cuadro 3. Primeras regionalizaciones realizadas por geógrafos argentinos (mediados del siglo $\mathrm{XX}$ )

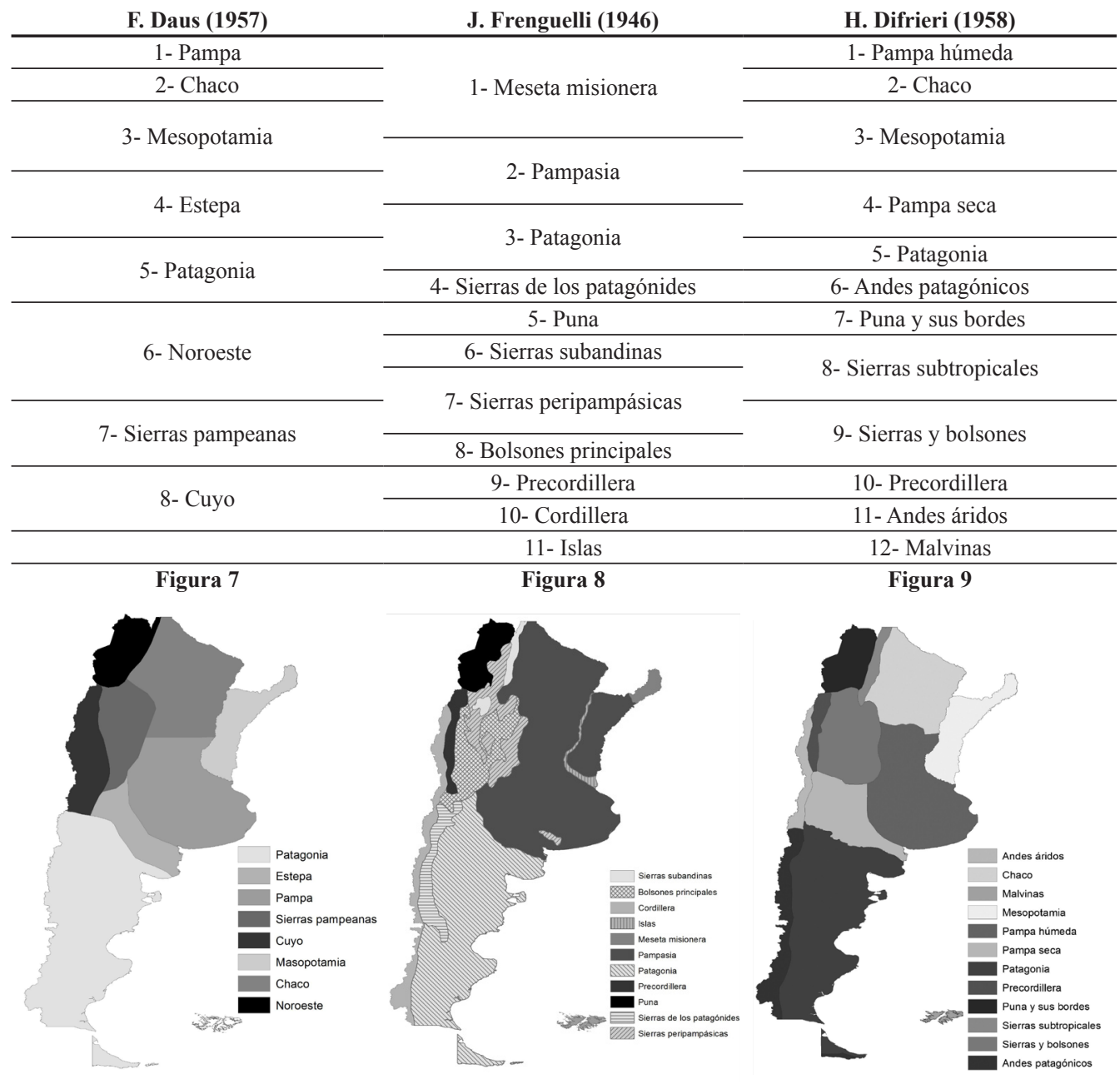

Fuente: Elaboración propia en base a Daus (1957), Frenguelli (1946) y Difrieri (1958). Cartografía digital: Pablo Maestrojuan. 
R. Rey Balmaceda (1972) presenta una síntesis consistente del programa de la geografía regional argentina impulsada por F. Daus, J. Frenguelli y H. Difrieri, entre otros autores. En este trabajo ofrece una serie de características de lo que él define como "enfoque regional", que coincide con lo que en la sección anterior se denominó "enfoque humano". A partir de algunas críticas realizadas a un trabajo de M. Zamorano (que se abordará en la próxima sección) sostenía que las "regiones geográficas" no pueden superponerse, ya que son contiguas. En este mismo orden, puso en dicho trabajo especial énfasis en la cuestión de la delimitación de las regiones, la cual debe ser precisa y no debería seguir líneas rectas (por considerar que estas no son geográficas, sino artificiales) y debe partir siempre de la consideración de las condiciones del medio natural. Finalmente, recuperando una serie de conclusiones realizadas en un congreso de la GÆA del año 1970, el autor resalta: “...la región geográfica es una realidad, y que corresponde a una parte de la superficie terrestre identificada dentro de un marco espacial definido, en el cual existen rasgos de homogeneidad genérica de los cuales derivan su cohesión interna y su unidad funcional..." (Rey Balmaceda, 1972:112113). Desde su perspectiva, los elementos del medio físico desempeñan todavía un papel muy importante en la determinación de las regiones geográficas, aunque admite que “...la economía constituye, en el enfoque estructural, un aporte valioso para el conocimiento y delimitación de las regiones geográficas.” (Rey Balmaceda, 1972:112113). En este orden, reconoce una diferenciación entre las "regiones estrictamente geográficas" y las denominadas regiones-plan o regiones-programas, a las que otorga una relevancia menor, por su carácter artificial. Finalmente, y a modo de balance, señala que "...ha habido asentimiento acerca de la necesidad de intensificar los estudios de carácter regional por parte de los institutos de investigación geográfica dependientes de las universidades y de los institutos superiores del profesorado" (Rey Balmaceda, 1972:112-113).

De esta manera, se pone de manifiesto el modo en el que paulatinamente la práctica de la regionalización se fue convirtiendo en la clave interpretativa por excelencia, así como en el quehacer fundamental, de los geógrafos argentinos de este periodo. La perspectiva regional dominante mantenía un marcado sesgo naturalista, con una fuerte impronta positivista. Esto se hacía patente en el carácter empiristas de las propuestas, donde no se explicitaba una sólida argumentación teórica, ni se daban mayores referencias de la estrategia metodológica seguida. En la mayor parte de los casos había, además, una total ausencia de referencias a las fuentes consultadas. Otro rasgo de gran importancia que caracteriza estos trabajos radica en la confluencia del pensamiento regional con el nacionalismo territorial. Esto se manifestaba de dos maneras: (a) la regionalización siempre se construía como un conjunto de unidades contiguas que nunca rebasaba los límites políticos, aunque se realizaban comentarios sobre las posibles continuidades (elemento que presenta cierta continuidad con las propuestas regionales anteriormente elaboradas); y (b) la consideración de áreas de soberanía controvertida como parte real del país, como por ejemplo las Islas Malvinas y la Antártida Argentina (elemento novedoso de estas propuestas). 
Benedetti y Salizzi. 150 años de geografía regional en Argentina: cambios y continuidades en las propuestas de...

d) Regionalizaciones realizadas por una segunda generación de geógrafos argentinos

A partir de la década de 1960 nuevas generaciones de geógrafos fueron introduciendo nuevas preocupaciones y enfoques, sin por ello romper abiertamente con la tradición ambientalista prevaleciente desde fines del siglo XIX. En este contexto surgen como trabajos más representativos los desarrollados por M. Zamorano (1964), E. Chiozza (1969 y 1974-1977) y J. Roccatagliata (1988) (ver Cuadro 4).

El trabajo elaborado por Zamorano (1964), presenta una propuesta de regionalización que contempla tanto las condiciones morfológicas e hidrográficas del territorio nacional, como la "individualidad manifestada por una vigencia histórica particular" (Zamorano, 1964:72). Basándose en los aportes de F. Daus, identifica ocho regiones que, de acuerdo con su perspectiva, han adquirido arraigo debido a la constancia de su señalamiento. Pero no es esta la regionalización que M. Zamorano finalmente va a desarrollar. Desde una perspectiva geohistórica, el autor presta atención al proceso de colonización y de desarrollo del capitalismo extractivo en el país. Luego de ensayar su visión sobre el desarrollo geográfico de la Argentina, avanza hacia una propuesta de regionalización, que no descarta las regiones geográficas de F. Daus, sino que se apoya en ellas. Las diez regiones resultantes surgen por la "acción humana en la conquista paulatina del suelo argentino" (Zamorano, 1964:89). Las denominaciones utilizadas dan cuenta de las actividades productivas predominantes en las áreas delimitadas (Figura 10). Zamorano presenta su regionalización en la última página de su texto, a modo de conclusión, sin avanzar en la descripción de cada una de ellas. Este trabajo ofrece algunas novedades: hay regiones que siguen líneas rectas (de explotación de petróleo), regiones que se superponen (ganadera, de explotación minera y de vida pastoril) y regiones discontinuas (azucarera), poniendo en cuestión los postulados de Rey Balmaceda, mencionado en el apartado anterior.

La obra más reconocida de Chiozza (1974 y 1977), se divide en seis tomos. En el primero de ellos se abordaba al país como totalidad, para posteriormente presentar en los restantes un análisis pormenorizado de las siguientes unidades regionales: I) el Noroeste; II) las Pampas; III) la Patagonia, IV) la Antártida Argentina, V) el Nordeste; VI) los Oasis serranos, VII) los Oasis cuyanos, VIII) el Chaco; y IX) la Región Metropolitana. Esta regionalización, que incluye denominaciones fisiográficas -como Pampas- y geohistóricas - como Cuyo- clásicas, tiene como novedad la inclusión de la Región Metropolitana como una unidad particular, en concordancia con la creciente importancia adquirida por la planificación regional (que se manifestaba a su vez en el protagonismo adquirido por instituciones como el Consejo Nacional de Desarrollo). La renovación de la propuesta desarrollada en este trabajo residía en la mayor relevancia otorgada a cuestiones económicas (como la estructura industrial) y sociales (como las desigualdades sociales manifestadas en el surgimiento de las barriadas populares). La propuesta que presenta, de todos modos, continúa mostrando un puzzle de regiones geográficas, pensadas como "espacios naturalmente diferenciados puestos en valor en distintos momentos históricos por poblaciones de diverso origen e intereses, que han ido desarrollando una serie de solidaridades locales a impulsos de la búsqueda de 
soluciones comunes" (Aranovich y Chiozza, 1977:2). De este modo, y de acuerdo con el creciente interés puesto en la historización de las entidades regionales, se advierten reminiscencias de la propuesta desarrollada por Denis (1920), obra que fuera traducida y comentada por la propia Chiozza. La impronta de la geografía regional francesa queda manifiesta, además, en la creciente utilización de la noción de "puesta en valor" en la lógica general que siguen sus planteos. Allí hace hincapié tanto en la importancia de las condiciones naturales de las regiones en cuestión, como en las diferentes formas que ha adoptado históricamente su puesta en valor de acuerdo con las posibilidades -sociales y materiales- que se han presentado a sus pobladores (Salizzi, 2012). En la Figura 11 se presenta una reconstrucción de la regionalización de marras.

Una última propuesta surgida en este periodo es la de Roccatagliata (1988), en el libro por él compilado, cuyo título expresa una forma clásica de distinción del conocimiento geográfico, en general y particular (o regional): "La Argentina. Geografía general y los marcos regionales” (1988). En la introducción a la parte regional, sobre la base de la propuesta desarrollada por Zamorano (1964), el autor introduce aportes de la geografía analítica, al pretender construir regiones basadas en el criterio de uniformidad y cohesión generadas por ciertas actividades. Sin embargo, puede apreciarse que la impronta naturalista sigue activa en sus postulados generales. Esto se pone de manifiesto al presentar la división regional adoptada, que sirve como índice para la segunda parte de la obra, donde afirma que "...las regiones formales obedecen a la concurrencia y correlación en un espacio dado de factores diversos del ámbito físico, biológico y de la vida humana pero la entrada en el análisis regional es la organización humana del espacio, y desde esa dominante se deben interpretar todas las correlaciones que generen finalmente un espacio conforme" (Roccatagliata, 1988:437-438). Identifica así ocho unidades, entre las que ubica - consolidando la impronta planificadora- a la Región Metropolitana de Buenos Aires. Otra continuidad que se evidencia en este trabajo, se encuentra en la impronta geopolítica clásica que presenta, la cual se pone de manifiesto al incluir a la "Región marítima antártica, un espacio cuestionado, con potencialidades y recursos de expectativa", dentro del cual incluye a las Islas Malvinas y al sector Antártico. En cuanto al criterio general de regionalización cabe señalar que si bien opera una lógica de zonificación, sostiene un principio flexible de delimitación, al sostener que los límites no pueden ser tajantes y proponer que conviene adoptar el trazado suelto que deja algo indecisas las zonas de contacto. En la Figura 12 se reconstruye el agrupamiento de provincias por él propuesto. 
ARTÍCULOS

Benedetti y Salizzi. 150 años de geografía regional en Argentina: cambios y continuidades en las propuestas de...

\section{Cuadro 4. Regionalizaciones realizadas a lo largo de la segunda mitad del siglo XX}

\section{Zamorano (1964)}

1- Concentración demográfica e industrial
E. Chiozza (1974-1977)

1- Región Metropolitana
J. Roccatagliata (1988)

1- Región metropolitana de Buenos Aires

\section{2- Ganadería seleccionada y cultivo} de granos
2- Las Pampas

2- Macro Región Pampeana (a. Eje urbano industrial del Plata-Paraná y

b. Pampa agroganadera con industrias urbanas y portuarias)

3- Ganadería menor extensiva

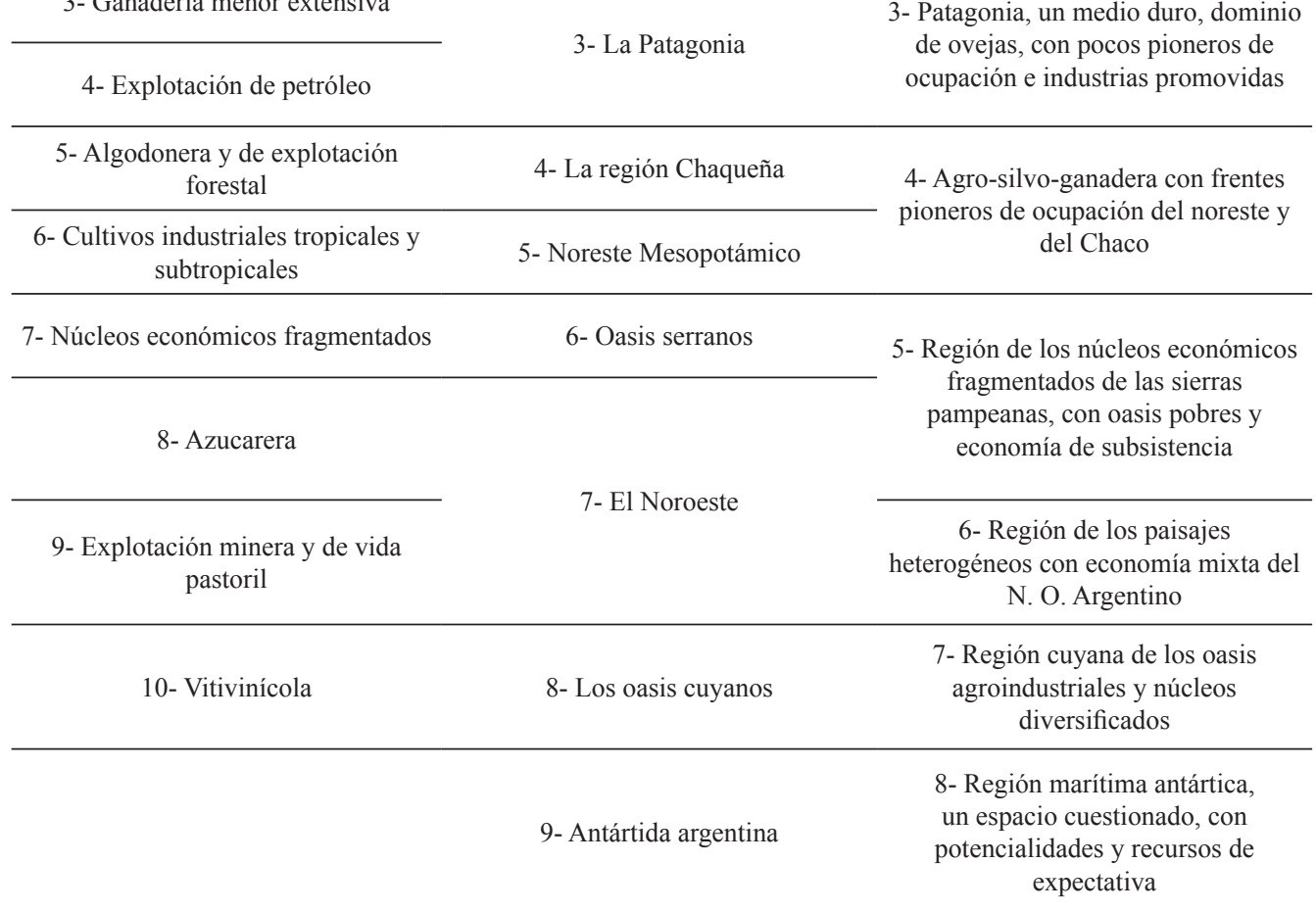

Figura 11

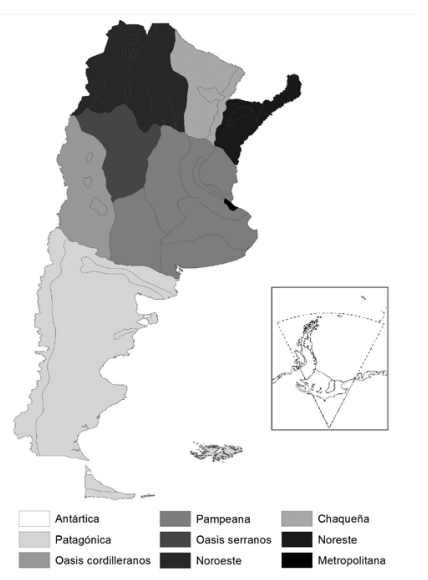

Figura 12

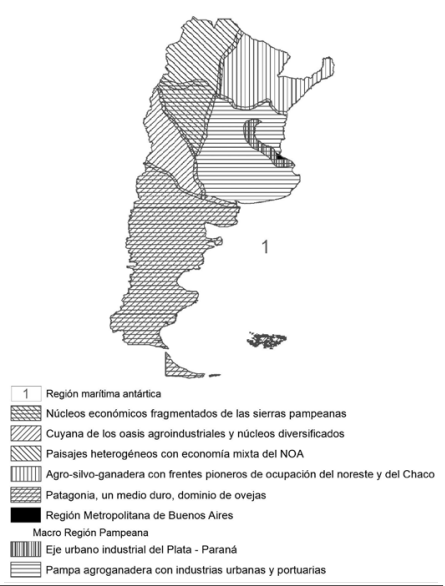

Fuente: Elaboración propia en base a Zamorano (1964), Chiozza (1974-1977) y Roccatagliata (1988).

Cartografía digital: Pablo Maestrojuan. 


\section{4) Regionalizaciones de la Argentina: continuidades y discontinuidades}

Desde una perspectiva político-cultural como la que orienta la hechura de este artículo, cabe destacar que la variable histórica adquiere una importancia significativa para el abordaje del proceso de institucionalización de cualquier región, pudiendo de este modo hacer referencia -en términos generales-a su emergencia, transformación y desaparición. Así, las regiones ya no son concebidas como entidades ontológicamente fijas, sino como estructuras dinámicas, en transformación, que están constituyéndose permanentemente a través de las prácticas materiales y simbólicas de la sociedad. Las regiones son, a la vez, procesos abiertos e históricamente contingentes. Estudiar las regiones o el discurso regional desde una perspectiva político-cultural implica tener en cuenta los contextos históricos de emergencia de dichas unidades, así como también la compleja trama de actores sociales que participaron tanto en su construcción material como en su definición imaginaria. Cada región que conocemos en el presente tuvo su origen en un momento determinado, $\mathrm{y}$ en su conformación estuvieron activos diferentes situaciones que remiten a diálogos interdisciplinares, agenda de las instituciones interesadas en esas regionalizaciones, puja entre grupos dentro la comunidad experta.

Aquí prestamos atención al proceso de división regional realizado sobre el territorio argentino de parte de profesionales naturalistas y geógrafos a lo largo de un siglo y medio. Todos los autores mencionados suelen referenciarse en sus antecesores y proponer su regionalización como una versión mejor ajustada, superadora de las anteriores y, a la vez, la tendieron a presentar como realidad objetiva, para cuya determinación solo era necesaria la mirada especializada, experta y legitimada del geógrafo profesional. Estas regionalizaciones tuvieron amplia trascendencia en la lectura que, en la Argentina, se realizó sobre las diferencias internas del país. Esas diferencias tendieron a desplazarse de la división provincial -y, por lo tanto, política- consideradas artificiales (por lo tanto poco relevantes en la formación del territorio nacional), hacia unidades fisiográficas o de paisaje, por lo tanto naturales (consideradas como verdaderamente geográficas). Este pasaje desde una preeminencia de la división provincial (cuya secuencia en orden alfabético estructuraba el índice de los libros de geografía argentina) hacia otra de la división en regiones geográficas (cuyo ordenamiento seguía generalmente criterios cartográficos: primero las del norte y al final las del sur) no fue solo un cambio epistemológico, o de perspectiva, sino de formación de una comunidad experta de geógrafos, que encontraron en la regionalización su marca diferenciadora con respecto a otras disciplinas. Esto sirvió para su legitimación científica y la institucionalización del campo de la geografía en el ámbito académico y de formación docente. Estos geógrafos, asimismo, fueron teniendo llegada a los círculos militares y geopolíticos, a los de la educación y formación docente y, desde la década de 1970, a los de la planificación. Esas interacciones pueden reconocerse en las propuestas regionales que aquí se presentaron en forma cronológica.

A modo de conclusión se presentará un cuadro que sintetiza la información presentada en este artículo (ver Cuadro 5). Algunas cuestiones a destacar son la permanencia del enfoque naturalista como base para la regionalización. De todas 
formas, a pesar de la ilusión de permanencia y fijeza de esta perspectiva, las divisiones regionales resultantes varían en su extensión, en su denominación y en su delimitación a lo largo del tiempo. Asimismo, las regionalizaciones van confluyendo con intereses de la época: mientras que en el período I la división provincial está presente en todas las propuestas (inclusive en el inicio del período II, en el trabajo de Delachaux), en los períodos siguientes las provincias dejan de ser tenidas en cuenta como elemento geográfico diferenciador. A partir del período III el programa de la geografía articula el temario regional con el geopolítico: así, surgen regiones que incluyen a Malvinas y Antártida, áreas sobre la que el estado argentino pretende extender su soberanía territorial efectiva. En el período IV, finalmente, se advierten las herencias de los períodos previos (abandono de las divisiones político-administrativas provinciales como elementos a considerar en la regionalización, énfasis naturalista y confluencia con la geopolítica), a su vez que se reconoce la impronta planificadora, por el ejemplo al considerar el NEA o la Región Metropolitana como unidades significativas.

\section{Cuadro 5. Continuidades y rupturas en el discurso regional nacional (1839-1988)}

\begin{tabular}{|c|c|c|c|c|}
\hline & $\begin{array}{c}\text { Período I } \\
(1839-1876) \\
\end{array}$ & $\begin{array}{c}\text { Período II } \\
(1908-1930) \\
\end{array}$ & $\begin{array}{l}\text { Período III } \\
(1946-1958) \\
\end{array}$ & $\begin{array}{l}\text { Período IV } \\
(1964-1988) \\
\end{array}$ \\
\hline $\begin{array}{l}\text { Autores } \\
\text { destacados }\end{array}$ & $\begin{array}{l}\text { W. Parish (1839) } \\
\text { V. Martin de Moussy } \\
(1864) \\
\text { H. Burmeister (1876) }\end{array}$ & $\begin{array}{l}\text { E. Delachaux (1908) } \\
\text { P. Denis }(1920) \\
\text { F. Kühn }(1930)\end{array}$ & $\begin{array}{l}\text { F. Daus (1957) } \\
\text { J. Frenguelli (1946) } \\
\text { H. Difrieri (1958) }\end{array}$ & $\begin{array}{l}\text { M. Zamorano (1964) } \\
\text { E. Chiozza (1974- } \\
\text { 1977) } \\
\text { J. Roccatagliata (1988) }\end{array}$ \\
\hline $\begin{array}{l}\text { Contexto } \\
\text { histórico }\end{array}$ & $\begin{array}{l}\text { Antes de las conquistas } \\
\text { militares: no incluye } \\
\text { la Patagonia (Martin } \\
\text { de Moussy, solo la } \\
\text { nombra), el Chaco y la } \\
\text { Puna de Atacama. }\end{array}$ & $\begin{array}{l}\text { Posterior a la } \\
\text { finalización del proceso } \\
\text { de delimitación del } \\
\text { territorio nacional. }\end{array}$ & $\begin{array}{l}\text { Posterior a la } \\
\text { provincialización de } \\
\text { las gobernaciones. } \\
\text { Ascenso nacionalismo } \\
\text { territorial: } \\
\text { incorporación de la } \\
\text { Antártida y las islas } \\
\text { Malvinas. }\end{array}$ & $\begin{array}{l}\text { Dictaduras militares } \\
\text { y consolidación } \\
\text { del nacionalismo } \\
\text { territorial. } \\
\text { Planificación regional y } \\
\text { económica. }\end{array}$ \\
\hline $\begin{array}{l}\text { Perfil socio- } \\
\text { profesional }\end{array}$ & $\begin{array}{l}\text { Naturalistas (excepto } \\
\text { Parish; era diplomático) } \\
\text { extranjeros formados } \\
\text { en Europa. }\end{array}$ & $\begin{array}{l}\text { Geógrafos extranjeros } \\
\text { formados en Europa. }\end{array}$ & $\begin{array}{l}\text { Primeros geógrafos } \\
\text { argentinos formados en } \\
\text { el país, con influencia } \\
\text { directa de los autores } \\
\text { del período anterior } \\
\text { (algunos formados } \\
\text { en otras disciplinas, } \\
\text { como H. Difrieri con } \\
\text { formación en historia). }\end{array}$ & $\begin{array}{l}\text { Sucesivas camadas de } \\
\text { geógrafos formados en } \\
\text { el país. }\end{array}$ \\
\hline $\begin{array}{l}\text { Contexto } \\
\text { institucional }\end{array}$ & $\begin{array}{l}\text { Inserción en sociedades } \\
\text { científicas de la época. } \\
\text { Patrocinio del Estado } \\
\text { argentino (excepto } \\
\text { Parish). }\end{array}$ & $\begin{array}{l}\text { Contratados para } \\
\text { formar parte de las } \\
\text { primeras instituciones } \\
\text { académicas nacionales } \\
\text { de formación de } \\
\text { geógrafos (Delachaux } \\
\text { y Khün). Visitante } \\
\text { (Denis). }\end{array}$ & $\begin{array}{l}\text { Miembros de la } \\
\text { Sociedad Argentina } \\
\text { de Estudios } \\
\text { Geográficos (GEA). } \\
\text { Participación activa en } \\
\text { la institucionalización } \\
\text { disciplinar de la } \\
\text { Geografía. }\end{array}$ & $\begin{array}{l}\text { Vinculados a GEA, } \\
\text { investigadores- } \\
\text { docentes, Geografía } \\
\text { institucionalizada. }\end{array}$ \\
\hline Enfoque & $\begin{array}{l}\text { Naturalista (pre- } \\
\text { disciplinar). }\end{array}$ & $\begin{array}{l}\text { Naturalista } \\
\text { (fisiográfico). } \\
\text { Humano. }\end{array}$ & $\begin{array}{l}\text { Naturalista } \\
\text { (fisiográfico). } \\
\text { Humano. }\end{array}$ & $\begin{array}{l}\text { Naturalista } \\
\text { (fisiográfico). } \\
\text { Humano. } \\
\text { Analítico. }\end{array}$ \\
\hline
\end{tabular}




\begin{tabular}{|c|c|c|c|c|}
\hline $\begin{array}{l}\text { Criterios } \\
\text { regionales } \\
\text { concurrentes }\end{array}$ & Jurisdiccional. & Jurisdiccional. & Geopolítico. & $\begin{array}{l}\text { Geopolítico. } \\
\text { Planificación. }\end{array}$ \\
\hline Función & $\begin{array}{l}\text { Propaganda nacional e } \\
\text { Europa. } \\
\text { Primeras } \\
\text { sistematizaciones } \\
\text { geográficas del país. }\end{array}$ & $\begin{array}{l}\text { Primeras obras } \\
\text { geográficas del } \\
\text { conjunto del país } \\
\text { desarrolladas desde } \\
\text { la disciplina. Obras } \\
\text { académicas. }\end{array}$ & $\begin{array}{l}\text { Compendio de } \\
\text { geografía regional } \\
\text { argentina de la época. } \\
\text { Obras académicas. } \\
\text { Divulgación científica } \\
\text { (Difrieri). } \\
\text { Trasposición didáctica } \\
\text { (Daus). }\end{array}$ & $\begin{array}{l}\text { Compendio } \\
\text { de geografía } \\
\text { regional argentina } \\
\text { (Roccatagliata). } \\
\text { Divulgación científica } \\
\text { (Chiozza y J. } \\
\text { Roccatagliata). } \\
\text { Obras académicas } \\
\text { (Zamorano). }\end{array}$ \\
\hline $\begin{array}{l}\text { Delimitación } \\
\text { de las regiones }\end{array}$ & $\begin{array}{l}\text { Líneas continuas y } \\
\text { fijas. } \\
\text { Coinciden con los } \\
\text { límites provinciales. }\end{array}$ & $\begin{array}{l}\text { Líneas continuas y } \\
\text { fijas. } \\
\text { No coinciden con } \\
\text { límites provinciales } \\
\text { (excepto Delachaux). }\end{array}$ & $\begin{array}{l}\text { Líneas continuas y } \\
\text { fijas. } \\
\text { Contraste o } \\
\text { transfiguración (Daus). } \\
\text { No coinciden con } \\
\text { límites provinciales. }\end{array}$ & $\begin{array}{l}\text { Líneas continuas, fijas, } \\
\text { pero porosas. } \\
\text { Superposición de } \\
\text { regiones (Zamorano, } \\
\text { Roccatagliata). }\end{array}$ \\
\hline $\begin{array}{l}\text { Lógica de } \\
\text { división } \\
\text { espacial } \\
\text { utilizada }\end{array}$ & Zonal, puzzle. & Zonal, puzzle. & Zonal, puzzle. & $\begin{array}{l}\text { Zonal, puzzle; junto } \\
\text { con líneas rectas, } \\
\text { superposiciones y } \\
\text { discontinuidad. }\end{array}$ \\
\hline $\begin{array}{l}\text { Unidades } \\
\text { regionales que } \\
\text { se introducen }\end{array}$ & $\begin{array}{l}\text { Pampa, Litoral } \\
\text { (provincias orientales } \\
\text { o ribereñas), Región } \\
\text { central, Mesopotamia, } \\
\text { Cuyo, Andes y } \\
\text { Patagonia (esbozo). }\end{array}$ & $\begin{array}{l}\text { Patagonia, Chaco, } \\
\text { Puna, Pampa occidental } \\
\text { (seca), Sierras } \\
\text { pampeanas, Cordillera. }\end{array}$ & $\begin{array}{l}\text { Noroeste, Estepa, } \\
\text { Islas (incluyendo a las } \\
\text { Malvinas). }\end{array}$ & $\begin{array}{l}\text { Noreste, Región } \\
\text { metropolitana, } \\
\text { Antártica y/o Región } \\
\text { marítima antártica. }\end{array}$ \\
\hline
\end{tabular}

Fuente: elaboración propia.

\section{Referencias bibliográficas}

Aranovich, C. y Chiozza, E. 1977. "División regional”, en: El país de los Argentinos, Tomo 1, Buenos Aires: Centro Editor de América Latina.

Barsky, A. 2000. “Auge y ocaso de las "Regiones Geográficas Argentinas” de Federico Daus: de un pasado con certezas a una actualidad de fragmentación". 2do Encuentro Internacional Humboldt, 23 al 27 de octubre de 2000, Mar del Plata.

Benedetti, A. 2009. "Los usos de la categoría región en el pensamiento geográfico argentino". Scripta Nova, Revista Electrónica de Geografia y Ciencias sociales, vol. XII, núm. 286. Barcelona: Universidad de Barcelona. <http://www.ub.es/ geocrit/sn/sn-286.htm>.

Benedetti, A. 2010. “Quebrada de Humahuaca: ¿hoya, unidad fisiográfica, región geográfica, ambiente o lugar? Estudio bibliográfico sobre la toponimia y el pensamiento geográfico regional argentino (siglos XIX y XX)" . Registros. Revista Anual de Investigación del Centro de Estudios Históricos ArquitectónicosUrbanos, año 7, núm. 7, Mar del Plata: Facultad de Arquitectura, Urbanismo y Diseño - UNMdP.

Benedetti, A. 2014. “¿Qué es la Puna? El imaginario geográfico regional en la construcción conceptual del espacio argentino (siglos XIX y XX)”, en: Benedetti, 
A. y Tomasi, J. (comps.) Espacialidades altoandinas. Nuevos aportes desde la Argentina. Tomo II: Interacciones con el "mundo de afuera", Buenos Aires: Editorial de la Facultad de Filosofía y Letras Universidad de Buenos Aires.

Burmeister, H. 1876. Description physique de la République Argentine. D’après des observations personnelles et étrangères, traducido por MAUPAS, Émile [1876], París: F. Savy.

Carballo, C. 2012 "Interpretación geográfica vidaliana de la Argentina de comienzos del Siglo XX: La valorización del territorio según Pierre Denis”. Estudios Rurales, vol. 1, núm. 2 .

Chiozza, E. 1977. El país de los Argentinos, Buenos Aires: Centro Editor de América Latina.

Daus, F. 1935 "Geografía regional, una orientación de la enseñanza de la geografía" Boletín de la Universidad Nacional de La Plata, Tomo XIX, $N^{\circ} 1$, La Plata.

Daus, F. 1945. Geografia de la República Argentina. Parte Física, Buenos Aires: Ángel Estrada Editores.

Daus, F. 1957. Geografía y unidad Argentina, Buenos Aires: Editorial Nova.

Daus, F. 1969. "Fundamentos para una división regional de la Argentina". Publicaciones del Instituto de Geografía, serie A, núm. 28, Buenos Aires: Universidad de Buenos Aires, Facultad de Filosofía y Letras, Instituto de Geografía "Romualdo Ardissone".

Delachaux, E. 1908. "Las regiones físicas de la República Argentina”. Revista del Museo de La Plata, (XV).

Denis, P. 1920. La République Argentine. La mise en valeur du pays, París: Armand Colin. Traducido por CHIOZZA, Elena [1987] como: La valoración del país: la República Argentina, 1920, Buenos Aires: Ediciones Solar.

Difrieri, H. 1958. "Las regiones naturales”, en: DE APARICIO, F. y H. DIFRIERI (dirs.) La Argentina: suma de geografía, Buenos Aires: Edición Peuser.

Du Graty, A. 1858. La Confédération argentine, París: Guillaumin et cik, editeurs.

Escolar, M.; Quintero, S. y Reboratti, C. 1994. "Geographical identity and patriotic representation in Argentina", en: HOOSON, D. (comp.) Geography and national identity, Oxford: Blackwell.

Frenguelli, J. 1946. "Las grandes unidades físicas del territorio argentino". GAEA, Geografía de la República Argentina, (3), Buenos Aires: Sociedad Argentina de Estudios Geográficos GAEA.

García Álvarez, J. 2006. "Geografía regional”, en: HIERNAUX, D. y A. LINDÓN (dirs.) Tratado de Geografía Humana, México: Anthropos, UAM.

González Bollo, H. 1999. "Estado, ciencia y sociedad: Los manuales estadísticos y geográficos en los orígenes de la Argentina moderna, 1852-1876”. Anuario IEHS, vol. 14.

Heffernan, M. 2009. "Histories of Geography”, en: Clifford, N.; Holloway, S.; Rice, S. P. y Valentine, G. (eds.) Key Concepts in Geography, London: SAGE. 
Hevilla, M. C. 2007. "Los viajeros de las alturas: narrativas de viajeros y científicos sobre Los Andes argentino-chilenos en el siglo XIX", en: Zusman, P.; Lois, C. y Castro, H. (comps.) Viajes y geografias, Buenos Aires: Prometeo.

Kühn, F. 1930. Geografía de la Argentina, Buenos Aires: Editorial Labor.

Latzina, F. 1888. Geografia de la República Argentina, Buenos Aires: Félix Lajouane editor.

Livingstone, D. 1992. "A brief history of Geography”, en: ROGERS, A. y H. VILES (eds.) The Student's Companion to Geography, Oxford: Blackwell.

Martin De Moussy, V. 1864. Description géographique et statistique de la Confédération Argentine, París: Librairie de Firmin Didot Fréres. Traducido por ACADEMIA NACIONAL DE HISTORIA [2005] como: Descripción geográfica y estadística de la Confederación Argentina, Buenos Aires: ANH.

Napp, R. 1876. La República Argentina, Buenos Aires: Impr. Sociedad Anónima.

Navarro Floria, P. 1999. "Un país sin indios. La imagen de la pampa y la Patagonia en la geografía del naciente estado argentino”. Scripta Nova, Revista Electrónica de Geografía y Ciencias sociales, núm. 51, Barcelona: Universidad de Barcelona. $<$ http://www.ub.edu/geocrit/sn-51.htm>.

Navarro Floria, P. 2008. "La construcción de la particularidad patagónica a través del discurso de las primeras Geografías regionales del territorio argentino". 3as Jornadas de Historia de la Patagonia, 6 al 8 de noviembre de 2008, San Carlos de Bariloche.

Navarro Floria, P. y Mc Caskill, A. 2001. "La "Pampa fértil" y la Patagonia en las primeras geografías argentinas (1876)". Biblio $3 W$, Revista bibliográfica de Geografia y Ciencias Sociales, vol. VI, núm. 319, Barcelona: Universidad de Barcelona. <http://www.ub.edu/geocrit/b3w-319.htm>.

Navarro Floria, P. y Williams, F. 2010. "La construcción y problematización de la regionalidad de la Patagonia en las geografías regionales argentinas de la primera mitad del siglo XX”. Scripta Nova, Revista Electrónica de Geografía y Ciencias sociales, vol. XIV, núm. 322, Barcelona: Universidad de Barcelona. <http://www. ub.edu/geocrit/sn/sn-322.htm>.

Paasi, A. 2002. "Place and region: regional worlds and words". Progress in Human Geography, vol. 26, issue 6.

Parish, W. 1839. Buenos Ayres and the provinces of the Rio de la Plata: their present state, trade, and debt; with some account from original documents of the progress of geographical discovery in those parts of South America during the last sixty years, London: J. Murray. Traducido por MAESO, Justo [1852] como: Buenos Aires y las Provincias del Río de la Plata: desde su descubrimiento y conquista por los españoles ( $1^{\circ}$ ed.), Buenos Aires: Imprenta de Mayo.

Quintero, S. 1999. “El país que nos contaron. La visión de Argentina en los manuales de geografía (1950-1997)". Entrepasados $N^{o} 16$, Buenos Aires.

Quintero, S. 2002a . "Geografía regional en la Argentina. Imagen y valorización del territorio durante la primera mitad del siglo XX". Scripta Nova, Revista Electrónica de Geografía y Ciencias sociales, vol. VI, núm. 127, Barcelona: Universidad de Barcelona. <www.ub.es/geocrit/sn/sn-127.htm>. 
Quintero, S. 2002b. “Del relato de viaje a la descripción geográfica. La narración del territorio argentino en las obras de Parish, Martín de Moussy, Burmeister y Napp". 3 ra Jornada Interdisciplinaria "Formas y representaciones del territorio y la ciudad”, 6 y 7 de septiembre de 2002, Facultad de Filosofía y Letras, Universidad de Buenos Aires.

Rey Balmaceda, R. 1972. Geografía regional. Teoría y aplicación, Buenos Aires: Ángel Estrada.

Roccatagliata, J. 1988. La Argentina, geografía general y los marcos regionales, Buenos Aires: Planeta.

Salizzi, E. 2012. "Continuidades y rupturas en el discurso regional argentino: El proceso de construcción conceptual de la Pampa". Mundo Agrario, vol. 12, núm. 24. En Memoria Académica. <http://www.memoria.fahce.unlp.edu.ar/art_revistas/ pr.5263/pr.5263.pdf>.

Souto, P. 1996. “Geografía y Universidad. Institucionalización académica y legitimación científica del discurso territorial en la Facultad de Filosofía y Letras de la Universidad de Buenos Aires". Territorio $N^{\circ} 8$, Buenos Aires: Instituto de Geografía, Facultad de Filosofía y Letras, Universidad de Buenos Aires.

Souto, P. 2003. "Patagonia: valorización económica, valorización política y discurso geográfico en la construcción de una identidad regional", en: Berdoulay, V. y Vargas, H. (eds.) Unidad y diversidad del pensamiento geográfico en el mundo. Retos y perspectivas, México: Universidad Autónoma de México-Instituto de Geografía.

Souto, P. y Ajón, A. 2004. "Imágenes y representaciones del territorio: región y provincias en el Noroeste argentino". Revista de Geografía Estudios Socioterritoriales, año IV, núm. 4, Facultad de Ciencias Humanas, Universidad del Centro de la Provincia de Buenos Aires.

Velázquez, G. 2001. Geografía, calidad de vida y fragmentación en la argentina de los noventa. Análisis regional y departamental utilizando SIG's. Buenos Aires: Universidad Nacional del Centro de la Provincia de Buenos Aires, CIG.

Velázquez, G. 2008. "Las regionalizaciones argentinas: evolución de su capacidad de discriminación del bienestar de la población (1943-1992)”. GeoFocus (Artículos), núm. 8 .

Zamorano, M. 1964. Las regiones geográficas de la República Argentina: Aportación a una clasificación fundada en la actividad humana. Seminario de Geografía de La Universidad de Murcia: Publicación D. Suc. de Nogués.

Zusman, P. 1997. "Una geografía científica para ser enseñada. La Sociedad Argentina de Estudios Geográficos (1922-1940)". Doc. Anàl. Geogr, 31. 